\title{
Letter to the Editor: Caution needed when using gridded meteorological data products for analyses in Africa
}

J Shaman (jls106@columbia.edu)1

1. Department of Environmental Health Sciences, Mailman School of Public Health, Columbia University, New York, NY, United States

Citation style for this article:

Shaman J. Letter to the Editor: Caution needed when using gridded meteorological data products for analyses in Africa. Euro Surveill. 2014;19(41):pii=20930. Available online: http://www.eurosurveillance.org/ViewArticle.aspx?Articleld=20930

Article submitted on 1 October 2014 / published on 16 October 2014

The recent paper by $\mathrm{Ng}$ et al., Association between temperature, humidity and ebolavirus disease outbreaks in Africa, 1976 to 2014 [1], addresses an important issue: whether there are meteorological conditions associated with the onset of human Ebola virus disease outbreaks. However, the findings presented in this study are undermined by the use of a gridded climate dataset built, for the region in question, on little-to-no actual meteorological data.

$\mathrm{Ng}$ et al. perform their analysis using University of East Anglia Climate Research Unit (CRU) gridded estimates of surface meteorological conditions [2]. This $0.5^{\circ}$ resolution global dataset merges monthly meteorological station observations with a global land surface climatology. The derived time series of CRU surface variables have been validated through comparison with other gridded climate products; however, these comparisons were made using hemispheric and other large regional spatial averages of the gridded data. Validation was not reported at the local $0.5^{\circ}$ resolution of the gridded data. Furthermore, Harris et al. found discrepancies from other gridded datasets 'mostly in regions and/or time periods with sparser observational data' [2].

$\mathrm{Ng}$ et al. used the CRU dataset to identify temperature and humidity conditions associated with the onset of 28 Ebola virus disease outbreaks in Africa during 1976 to 2014. All the Ebola virus disease outbreaks included in this analysis, with the exception of the current West African Ebola virus disease outbreak, occurred in central Africa between $8-34^{\circ} \mathrm{E}$ and $7^{\circ} \mathrm{S}-6^{\circ} \mathrm{N}$ (Figure 1 ). Within this region of more than 3 million $\mathrm{km}^{2}$, during 1976 to 2012 , fewer than 40 stations per month provided temperature data for construction of the CRU dataset and no stations provided humidity (i.e. vapour pressure) data (Figure 2). Indeed, since 1992, on average fewer than seven stations per month provided temperature data for construction of the CRU dataset.

The CRU dataset uses a land surface climatology and a correlation decay distance (CDD) that spatially interpolates station records to inform estimates in all grid cells, including those without stations [2]. Even after accounting for this CDD, there are regions of central Africa with no station temperature record signal, and most of Africa has no vapour pressure signal (Figure 3).

These issues are not minor. The CRU dataset is designed and validated for large-scale climate analyses; however, the analysis performed by $\mathrm{Ng}$ et al. explored local conditions associated with the onset of specific Ebola virus disease outbreaks. The CRU dataset is likely not appropriate for this analysis; consequently, the $\mathrm{Ng}$ et al. study conclusions must be qualified. In other instances, for example, in analyses of meteorological conditions associated with malaria in the Kenyan highlands, the findings made using the CRU dataset

\section{FIGURE 1}

Locations of Ebola virus disease outbreaks included in the analysis of $\mathrm{Ng}$ et al. [1].

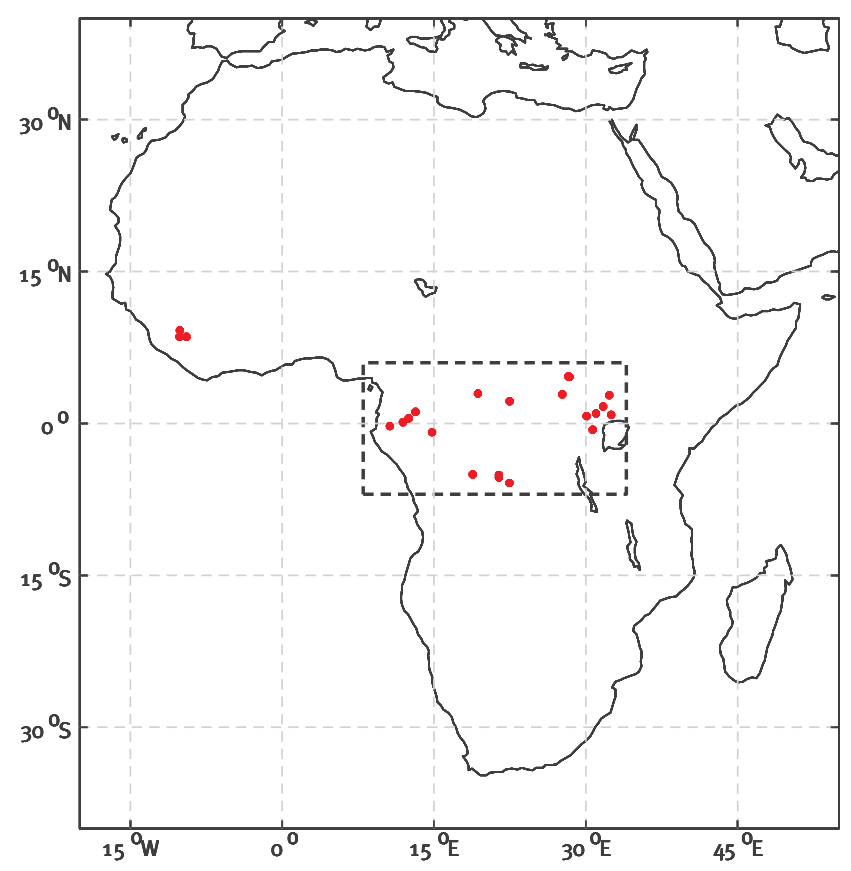

The dashed box outlines the region $\left(7^{\circ} \mathrm{S}-6^{\circ} \mathrm{N}, 8-34^{\circ} \mathrm{E}\right)$ in which the majority of Ebola virus disease outbreaks have occurred. 
were significantly different from those made using a richer complement of station observations, accessed through collaboration with the Kenyan Meteorological Department [3]. Unfortunately, local meteorological station records are often non-existent or difficult to access in much of Africa.

Study of the relationships between meteorological conditions and infectious disease outbreaks is important research. It is vital the best meteorological records be identified, made available and used for these analyses
[4], and that these analyses be postponed or qualified in the absence of good records.

\section{Acknowledgements}

Funding was provided by United States National Institutes of Health grants $\mathrm{GM}_{100467}$ and $\mathrm{GM}_{110748}$, as well as National Institute of Environmental Health Sciences Center grant ESo09089 and the RAPIDD programme of the Science and Technology Directorate, United States Department of Homeland Security.

\section{FIGURE 2}

Time series of total station records for the region $7^{\circ} \mathrm{S}-6^{\circ} \mathrm{N}, 8-34^{\circ} \mathrm{E}$ used in construction of the University of East Anglia Climate Research Unit dataset

A Temperature

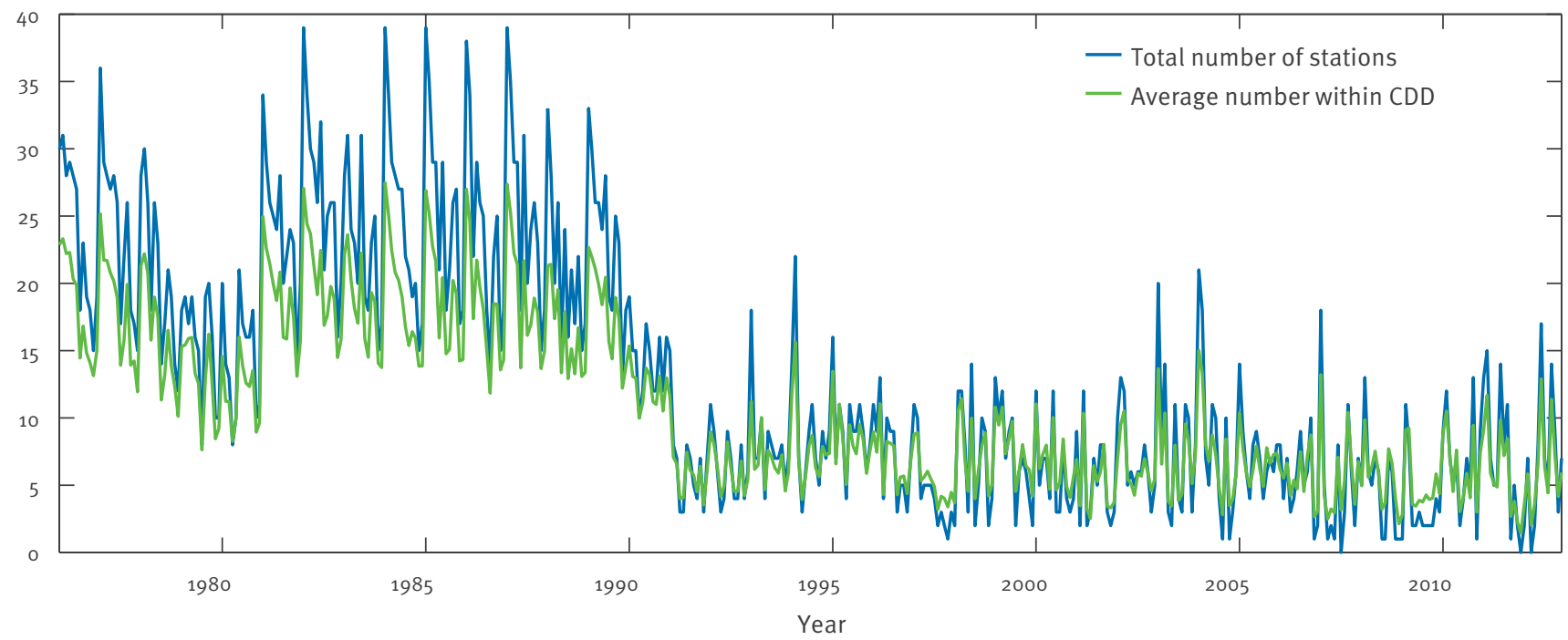

B Vapour pressure

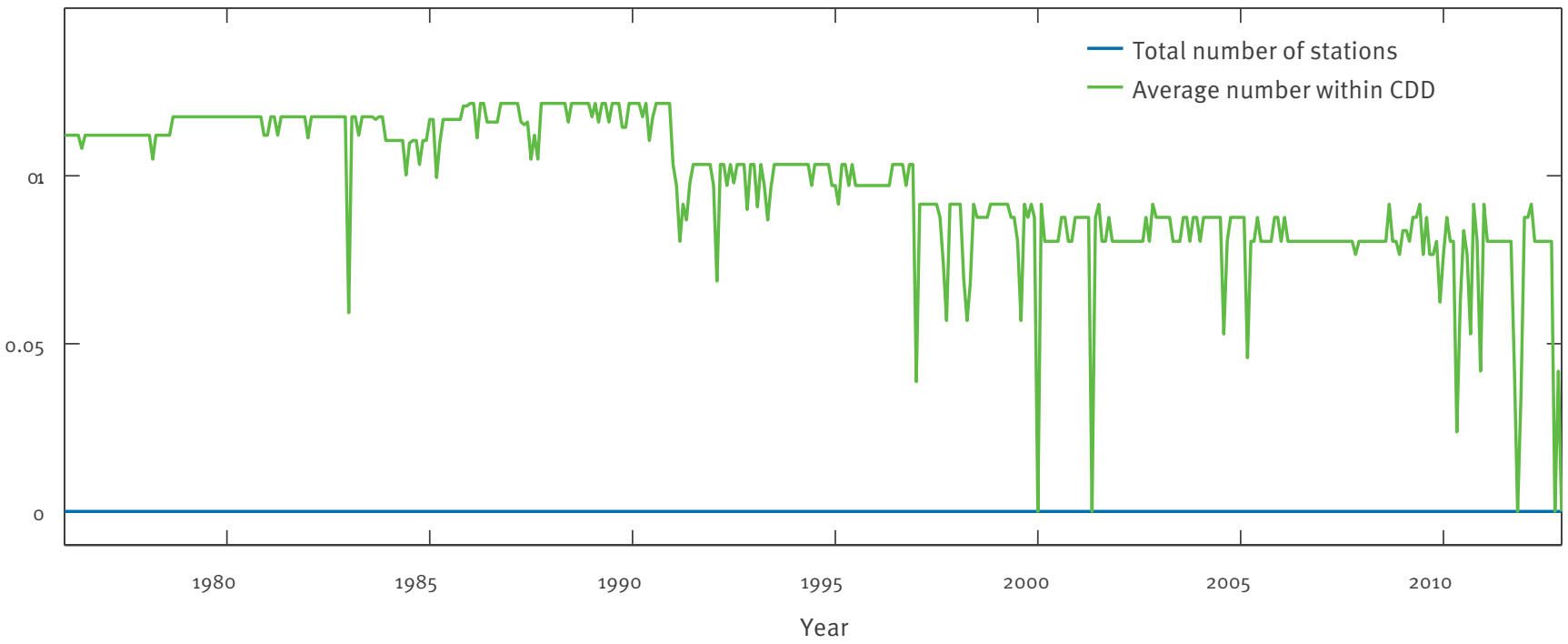

CDD: correlation decay distance.

Time series of total station records used in construction of the University of East Anglia Climate Research Unit dataset within the region $7^{\circ} \mathrm{S}-6^{\circ} \mathrm{N}, 8-34^{\circ} \mathrm{E}$ (green), as well as the mean number of station records within the CDD of each grid cell within that region (blue). Shown for temperature (panel A) and vapour pressure (panel B). 


\section{Conflict of interest}

The author discloses consulting for JWT and Axon Advisors.

\section{References}

1. Ng S, Basta NE, Cowling BJ. Association between temperature, humidity and ebolavirus disease outbreaks in Africa, 1976 to 2014. Euro Surveill. 2014;19(35): pii=20892.

2. Harris I, Jones PD, Osborn TJ, Lister DH. Updated highresolution grids of monthly climatic observations - the CRL TS3.10 Dataset. Int J Climatol. 2013;34:623-42.

3. Omumbo JA, Lyon B, Waweru SM, Connor SI, Thomson MC. Raised temperatures over the Kericho tea estates: revisiting the climate in the East African highlands malaria debate. Malaria J. 2011;10:12
4. International Research Institute for Climate and Society (IRI). A gap analysis for the implementation of the Global Observing System Programme in Africa. Palisades, NY: IRI; 2006. Available from: http://iri.columbia.edu/docs/publications/ GapAnalysis.pdf

\section{FIGURE 3}

Plots of distribution station records included in construction of the University of East Anglia Climate Research Unit dataset for January 1996

\section{A. Stations' temperature records per grid cell}

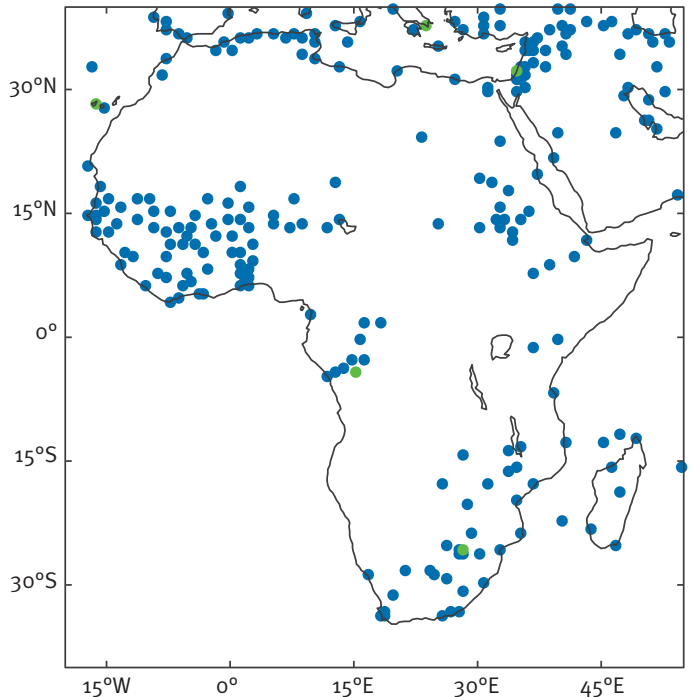

C. Stations' temperature records within the CDD of each grid cell

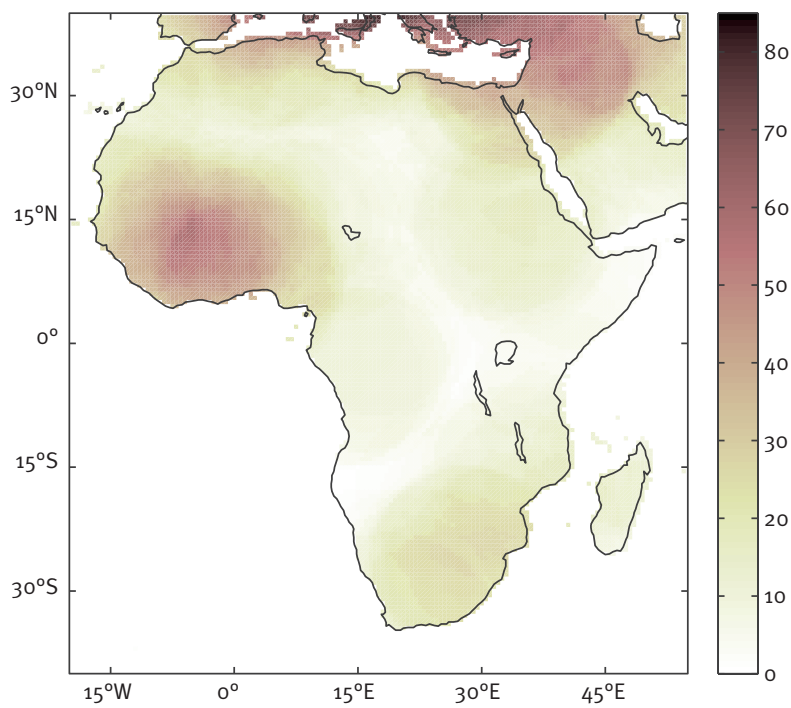

B. Stations' vapour pressure records per grid cell

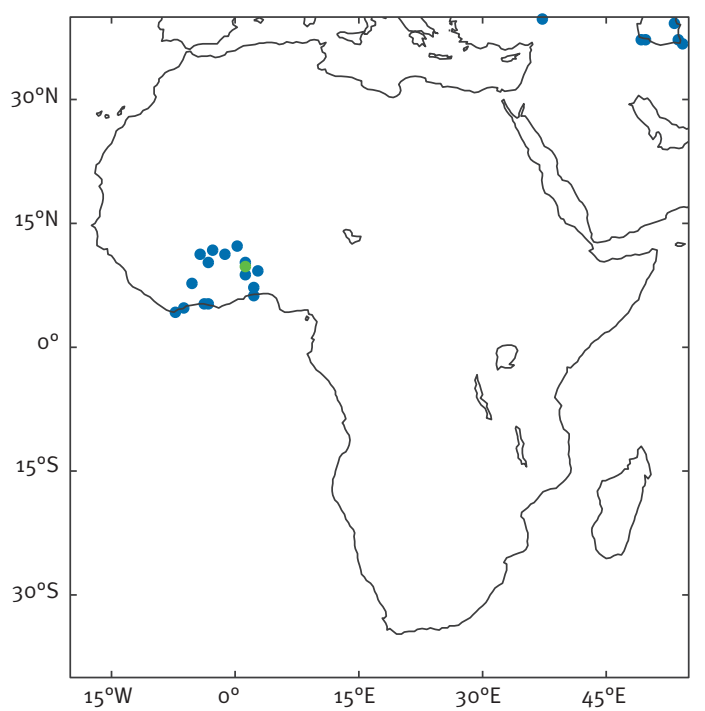

D. Stations' vapour pressure records within the CDD of each grid cell

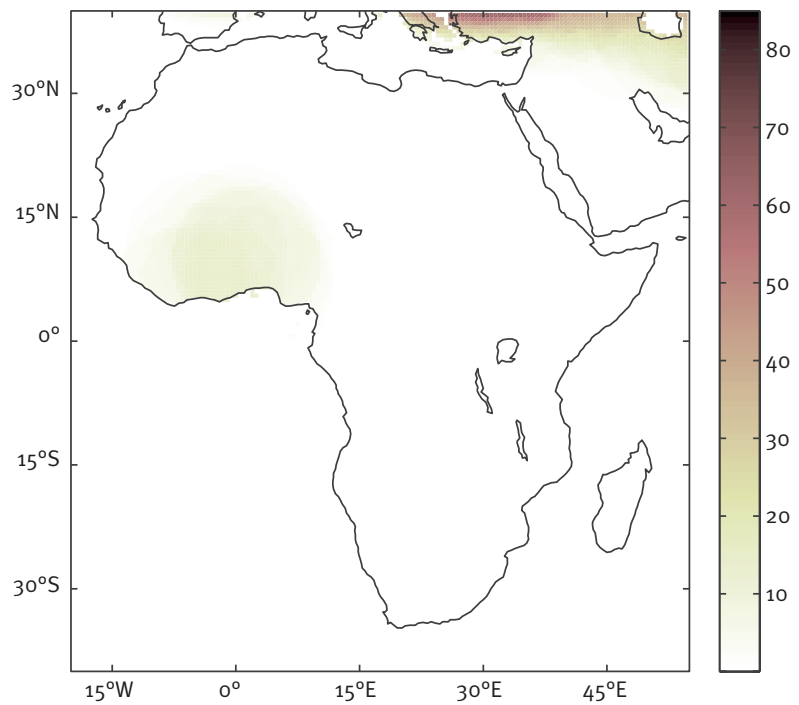

CDD: correlation decay distance.

In panels $A$ and $B$, blue dots indicate one station, green dots indicate two stations. 